\title{
La conformación de una política exterior mexicana en torno al corolario Roosevelt a la Doctrina Monroe, 1904-1906*
}

Diana Corzo González

INSTITUTO MORA

\begin{abstract}
Entre 1904 y 1906, el presidente Roosevelt y el secretario de Estado Root, manifestaron a la representación mexicana en Estados Unidos su deseo de que las naciones latinoamericanas sostuvieran el corolario Roosevelt a la Doctrina Monroe. El ensayo reflexiona sobre esta propuesta y las acciones del gobierno mexicano dentro del contexto internacional.
\end{abstract}

PREÁMBULO

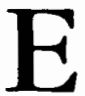
ste ensayo pretende dilucidar el significado del corolario Roosevelt de 1904 a la Doctrina Monroe para el gobierno mexicano y para su relación con Estados Unidos. Es un estudio que debe entenderse con el trasfondo del contexto internacional de ese entonces, en el que el

- Agradezco al doctor Paolo Riguzzi la sugerencia temática, así como sus valiosos comentarios y constantes revisiones; también a Carlos Campos por su generoso apoyo. El contenido es responsabilidad mía. país vecino del norte estaba desempenando una activa política exterior en América Latina, especialmente en el Caribe y Centroamérica.

Se analizará cómo se resolvió un problema concreto: la formulación de una respuesta en torno al planteamiento que el presidente Theodore Roosevelt hiciera a la representación diplomática mexicana en Estados Unidos, respecto a que de manera conjunta las naciones americanas se pronunciaran a favor de su interpretación de la Doctrina Monroe. Se busca además de entender la reacción del Estado mexicano y cómo se presentó, reflexionar sobre el 
tipo de acciones que puede emprender en política exterior un estado débil ante uno hegemónico, es decir en una relación asimétrica. ${ }^{1}$

La riqueza de la información que presentamos reside en que proviene del archivo personal de José Yves Limantour, ministro de Hacienda, quien tenía en ese entonces, un peso político muy importante. ${ }^{2}$

El ensayo está organizado en tres partes: la primera presenta una revisión del contexto en el que se enunció el corolario Roosevelt en 1904; la segunda se refiere a la serie de propues-

\footnotetext{
${ }^{1}$ Consideramos política exterior a la serie de acciones que realiza un Estado en el ámbito internacional. Se forma a través de medidas que responden a "motivaciones y aspiraciones, formulan intereses, analizan situaciones, seleccionan objetivos y deciden y ejecutan vías de acción" en Atkins, América, 1992, p. 23. La política exterior puede responder a un proyecto estatal o de interés nacional-fijado por el líder político de un Estado en poder o por el grupo de personas que detentan el poder- o responder a una circunstancia internacional. En tanto que la asimetría se mide por la diferencia de recursos potenciales (sociales, económicos y militares) que existe entre dos naciones, Duroselle, Todo, 1998, pp. 125, 208-221 y 243-263.

${ }^{2}$ Limantour estudió en la Escuela Nacional de Jurisprudencia; impartió clases en la Escuela Superior de Comercio y en la de Jurisprudencia. Formó parte de la comisión que en 1877 estudió la conveniencia de celebrar un tratado con Estados Unidos, en la que emitió un juicio adverso; realizó análisis de la baja de la plata, y en 1893, asumió el cargo de secretario de Hacien. $\mathrm{da}$, donde destacó, entre otras cosas, por nivelar el presupuesto, eliminar alcabalas, atender asuntos monetarios de instituciones bancarias y de deuda. En 1898 se habló de su candidatura a la presidencia para el periodo 1900-1904 apoyado por los "científicos" y en 1904 para la vicepresidencia. Díaz, Limantour, 1910.
}

tas estadunidenses presentadas a la embajada mexicana en relación con esa nueva interpretación de la Doctrina Monroe, y la última incluye las diferentes reacciones del gobierno mexicano ante dichas iniciativas así como reflexiones finales.

\section{El COROLARIO ROOSEVELT. AMÉRICA LA'TINA Y MÉXICO}

Si bien es cierto que la Doctrina Monroe $^{3}$ se enriqueció en conceptos a lo largo' del siglo XIX, ${ }^{4}$ no tuvo repercusiones concretas en el ámbito internacional porque tampoco el potencial naval y militar estadunidenses se había consolidado lo suficiente como para

${ }^{3}$ El mensaje del presidente James Monroe, pronunciado en 1823 , mencionó cuatro ideas a las que luego se les conoció como doctrina; éstos fueron: el continente americano no estaba sujeto a nuevas colonizaciones por parte de potencias extracontinentales; los gobiernos americanos eran distintos e independientes de los europeos; Estados Unidos consideraría un ataque a su paz y seguridad cualquier intento de intervención de Europa en el continente americano y no intervenía ni intervendría en las colonias europeas existentes en ese momento ni en los asuntos internos de esas potencias. Velasco, EUA, 1988, vol. 8, p. 292.

${ }^{4}$ El presidente Polk, en diciembre de 1845 , añadió a la doctrina su oposición a cualquier injerencia europea en las relaciones entre dos estados americanos. Con Ulyses S. Grant se senal6 que los territorios americanos no podían ser transferidos a una potencia europea; posteriormente se indicó que la construcción de un canal interoceánico en América violaba los principios de la Doctrina Monroe, y en 1875 se planteó la intervención estadunidense como forma de prevenir injerencias europeas en América. Perkins, Historia, 1964. 
respaldarla. Las diferentes intervenciones europeas en América Latina nos reflejan la poca eficacia del dogma. ${ }^{5}$

En Estados Unidos fue cobrando importancia la necesidad de resolver la disparidad que tenían ante la Gran Bretaña respecto a su potencial marítimo y militar, hacia la década de los ochenta del siglo XIX y se comenzaron a destinar fondos para la adquisición de acorazados y torpederos, a fin de poder estar en mejor posición para defender lo que consideraban su patio de atrás: América Latina.

Estas medidas se relacionan con una reorientación de la política exterior estadunidense, interesada cada vez más en estimular su liderazgo económico y político en el continente. ${ }^{6}$ Dos sucesos que la ejemplifican fueron su participación en la solución de los problemas fronterizos entre Venezuela y la Guyana británica en $1895^{7}$ y en la guerra contra

${ }^{5}$ Perkins, ibid., pp. 157-159.

${ }^{6}$ Ibid., pp. 156-157. Respecto a la creación de una esfera de influencia estadunidense, el secretario de Estado, James G. Blaine, estuvo interesado en fomentar el panamericanismo bajo la batuta de Estados Unidos, por lo que promovió la primera conferencia interamericana en Washington en 1889, Bethell, Historia, 1991 , pp. $77-79$.

${ }^{7}$ En 1875 Estados Unidos ya había propuesto, sin éxito, su intermediación en ese problema; incluso las dos naciones sudamericanas rompieron relaciones en 1886 . Sin embargo, la idea fue semilla del arbitraje obligatorio que se estableció. Véase el artículo de Mónica Toussaint en esta misma revista. Fue en 1895 cuando el secretario de Estado, Richard Olney, manifestó que el problema entre Venezuela y la Guyana se relacionaba con el mensaje de Monroe e insistió en el arbitraje estadunidense, que se aceptó por medio de un tratado firmado en 1897, en el marco de las preocupaciones británicas por los
España en 1898, que significó la consolidación de su papel hegemónico en América, porque tras la derrota hispana, Estados Unidos adquirió en América Puerto Rico y el control político de Cuba. $^{8}$

El corolario Roosevelt se originó ante una serie de circunstancias: el recelo estadunidense respecto a que Alemania apoyara proyectos promovidos por algunos pangermanistas en la zona del Caribe;? la participación de Alemania, Italia e Inglaterra en un bloqueo contra Venezuela entre 1902 y 1903 , a fin de que el presidente Cipriano Castro cum-

conflictos con los boers en África del Sur y por una probable amenaza alemana en la región americana, Bethell, Historia, 1991, pp. 81-82.

${ }^{8}$ Primero hubo un control directo por un gobierno castrense de Estados Unidos hasta 1902; luego, por la enmienda Platt, uno indirecto, pues se añadieron a la Constitución cubana limitaciones políticas respecto a la contratación de deudas y acuerdos militares con potencias extranjeras, así como también se dio a los estadunidenses la posibilidad de intervenir en la isla en determinadas circunstancias y de comprar o arrendar tierras para explotar carbón o establecer bases navales, ibid., pp. 84-86.

${ }^{9}$ Algunos integrantes de la marina aiemana se habían mostrado interesados en adquirir, en 1896, las Indias Occidentales Danesas, como Ernst von Halle; o el almirante von Tirpitz, que impulsó hacia 1898 la idea de establecer una base naval en el Caribe, y en 1900, propuso a la Comisión de Presupuesto del Imperio fijar una base naval en Brasil e incluso, en 1902, manejó la idea de construir un canal interoceánico en Panamá con capital europeo. Si bien Perkins nos señala que el gobierno y el ministerio de Relaciones germanos fueron moderados e ignoraron las ideas de los pangermanistas, la pre. sencia alemana en inversiones, relaciones y de tipo militar preocupó a Estados Unidos, Perkins, Historia, 1964, pp. 174-187, y Bethell, Historia, 1991, pp. 86-88. 
pliera con el pago de sus deudas; ${ }^{10}$ las agitaciones en Centroamérica en contra del presidente guatemalteco Manuel Estrada Cabrera, y la posibilidad de una nueva intervención, esta vez en Santo Domingo.

Con estos precedentes, el secretario de Estado, Elihu Root, leyó un mensaje el 20 de mayo de $1904^{11}$ donde anunció las ideas del corolario que el presidente Theodore Roosevelt confirmó en su discurso de diciembre del mismo año:

No es verdad que Estados Unidos sienta hambre de tierras $[\ldots]$ Todo lo que este país desea es ver a sus vecinos estables [...] Cualquier país en el que su gente se conduzca bien, puede contar con nuestra profunda amistad [...] Pero los comportamientos incorrectos crónicos [...] pueden requerir en América o en algún otro lugar, la intervención de alguna nación civilizada, y en el Hemisferio Occidental el apego de Estados Unidos a la Doctrina Monroe puede forzarlos [...] a ejercer un poder internacional policial. ${ }^{12}$

${ }^{10} \mathrm{El}$ problema venezolano fue finalmente sometido al tribunal de La Haya, que en 1905 avaló el bloqueo, en Perkins, Historia, 1964, p. 198.

${ }^{11} \mathrm{El}$ mensaje fue leído ante los asistentes a una reunión que celebraba el segundo año de vida independiente de Cuba.

${ }^{12}$ Gantenbein, Evolution, 1971, pp. 361-362 (La traducción es mía). Cabe señalar también que el presidente James Buchanam (18571861), ya tenía en mente que Estados Unidos debía cumplir una función policial en el Caribe y Centroamérica, para mantener el orden y evitar la intervención de potencias europeas, Bethell, Historia, 1991, p. 76.
Estas declaraciones se relacionaban directamente con problemas de Santo Domingo con sus acreedores, que terminaron con la fiscalización estadunidense de sus aduanas, es decir se acudió a la aplicación del corolario Roosevelt.

Si bien es cierto que Venezuela y Santo Domingo quedaron satisfechos por la mediación estadunidense en la solución de sus problemas, Argentina y México se opusieron al despliegue de fuerzas en esos países y al discurso justificador de la política del "gran garrote" (big stick), como se le llamó a la empleada por Roosevelt. Sobre todo, después de observar las condiciones en las que se había obtenido la independencia cubana y posteriormente la de Panamá en 1903.

Hubo tres alternativas por parte de América Latina, que se opusieron a cualquier política exterior expansiva entre fines del siglo XIX y principios del XX. La primera, que se manejó entre 1868 y 1896, fue la doctrina del argentino Carlos Calvo, y consistió en un principio de defensa ante las naciones extranjeras. Abogaba por la soberanía nacional y la aplicación de tratamiento nacional a los extranjeros y sus intereses. ${ }^{13}$ Posteriormente, hubo un rechazo al intervencionismo estadunidense en los problemas latinoamericanos por parte del gobierno mexicano a través de lo que se conoció como la Doctrina Díaz, que fue un mensaje que el presidente de México pronunció ante el problema de límites entre Venezuela y la Guyana británica en 1895 , y en él manifestó su

${ }^{13}$ Ibid., p. 91. 
oposición al papel de Estados Unidos como defensor del continente ante las invasiones europeas. ${ }^{14}$

Otra reacción importante fue la doctrina impulsada por el doctor argentino Luis Drago en 1902, ante la intervención en Venezuela, que afirmaba que las deudas contraídas por una nación con otra no debían ser cobradas mediante el uso de la fuerza. ${ }^{15}$

\section{INCIATIVAS Y OFERTAS ESTADUNIDENSES}

Joaquín D. Casasús ${ }^{16}$ llegó a Washington con el cargo de embajador de México a fines de 1905. Apenas presentó sus cartas credenciales cuando el presidente Theodore Roosevelt le manifestó su deseo de tratar con él sobre la política estadunidense respecto a los

14 Riguzzi, "México", 1989, pp. 412-425, y
SRE, Siglo, 1935, pp. 188-191.
15 Riguzzi, "México", 1989, pp. 412-425.
${ }^{16}$ Casasús estudió en el Instituto Cientíico y Literario de Mérida y luego en la Escuela de Jurisprudencia en la ciudad de México. En 1880 fue secretario de gobierno en su estado natal, Tabasco; dirigió la secretaría del Banco Internacional e Hipotecario e impartió clases en la Escuela de Ingeniería y en la de Jurisprudencia. Intervino en la elaboración del Código de $\mathrm{Co}-$ mercio de la Ley de Instituciones de Crédito y de la Ley Monetaria. Obtuvo el fallo favorable a México en el caso de El Chamizal, zona en disputa en la frontera norte de México. Así mismo cultivó la literatura, fue uno de los fundadores del Liceo Altamirano y participó en la Academia Mexicana. Carreño, Joaquín, 1920. La elección de Casasús como embajador nos habla del interés del gobierno mexicano porque su representante en Washington fuera una persona con una sólida formación intelectual, acorde con el nivel al que se habia otorgado a las relaciones con Estados Unidos, pues desde 1889 la Legación mexicana fue transformada en embajada. países de Centro y Sudamérica, pues le parecía que algunas de esas naciones no la habían comprendido y

juzgaba que era conveniente, cuando estas naciones tuvieran necesidad de ser protegidas contra agresiones procedentes del extranjero, hacer alguna declaración colectiva y seguir una acción común, para fijar el alcance de la Doctrina Monroe. ${ }^{17}$

Es decir, que el presidente estadunidense buscaba fijar una medida por la cual las naciones latinoamericanas le permitieran intervenir cuando tuvieran problemas con algún país europeo e incluso hizo algunas sugerencias:

[...] cree que el gobierno de México puede sentirse halagado con un engrandecimiento territorial; $y$ debido a esta errónea idea $[\ldots]$ ha hablado de que Cuba debe ser un estado de la república mexicana; que estaría dispuesto a cedernos Puerto Rico y aun la administración de Santo Domingo, fundándose en que la igualdad de origen, de lengua $y$ de legislación, facilitaría mucho la realización de los grandes propósitos que el gobierno Americano tiene para con aquellos países.

Su idea principal es que México debe anexarse a la América Central, o que bajo su influencia se lleve a cabo la unificación de todas esas "repúblicas turbulentas", como él las llama. ${ }^{18}$

${ }^{17}$ Carta de Joaquín D. Casasús a José Yves Limantour, Washington, 11 de noviembre de 1905 en Centro de Estudios de Historia de México CONDUMEX (en adelante CONDUMEX), Archivo Limantour, fondo CDLrv, rollo 32 , carpeta 7, año 1905.

${ }^{18}$ Carta confidencial de Casasús a Liman. tour, Washington, 17 de noviembre de 1905 , en ibid. 
Casasús se limitó a declarar que en la historia de México se podía constatar que el país jamás se había interesado en aumentar su territorio a expensas de sus vecinos. Sin embargo, no era la primera vez que Roosevelt hacía insinuaciones a la representación mexicana en Estados Unidos respecto a un engrandecimiento territorial por parte de México. Al primer embajador, Manuel de Azpiroz, ${ }^{19}$ le llegó a manifestar en 1904 su simpatía por la idea de que México prolongara sus fronteras hasta Panamá, pues consideraba que ello contribuiría a eliminar los frecuentes conflictos existentes en el área centroamericana. ${ }^{20}$

Por otra parte, el 19 de noviembre de 1905 el ministro chileno, Walker Martínez ofreció una reunión al secretario de Estado, Elihu Root, a la que asistieron además el subsecretario, Robert Bacon, los embajadores de Brasil y México y los ministros de otros paí-

${ }^{19}$ Azpiroz fue jefe político de su natal Puebla y diputado al Congreso Constituyente de 1857. Se desempeñó como oficial mayor de la Secretaría de Relaciones en 1868, 1871, 1890 y 1898. En 1872 participó como agente y abogado de México ante la Comisión Mixta de Reclamaciones entre México y Estados Unidos, luego fue cónsul en San Francisco, y entre 1873 y 1875, se desempeñó como senador en el Congreso mexicano. Fue subsecretario de Relaciones, escribió un Código de extranjería y como se mencionó, fue el primer embajador de México en Estados Unidos, una vez que a las representaciones de ambos países se les dio dicho rango en 1889. Diccionario, 1981.

${ }^{20}$ De Azpiroz a Ignacio Mariscal, Washing ton, notas reservadas del 15 y 24 de diciembre de 1904 en Archivo Histórico de la Secretaria de Relaciones Exteriores de México, Archivo de la Embajada de México en Estados Unidos de América (en adelante AHSREM-AEMEUA), t. 189. ses americanos. ${ }^{21}$ En ella se planteó la conveniencia de organizar la tercera Conferencia Panamericana y el secretario Root comentó que si se escogía a Brasil como sede, era probable que él mismo fuera a inaugurar el evento y a participar por unos días en las sesiones de trabajo; pero agregó:

Ha llegado el tiempo [...] de que la Doctrina Monroe $[. .$.$] quede establecida de-$ finitivamente; y que sean las mismas repúblicas de la América las encargadas de hacerla cumplir, cada vez que alguna de ellas pudiera ser víctima de un ataque por parte de potencias europeas. ${ }^{22}$

Los dirigentes políticos de Estados Unidos proponían que un elemento de su política exterior (el corolario a la Doctrina Monroe) se convirtiera en política internacional ${ }^{23}$ y fuese sostenido por las naciones del continente

${ }^{21}$ Argentina, Bolivia, Colombia, Costa Rica, Cuba, Guatemala, Haití, Nicaragua, Panamá y Santo Domingo.

${ }^{22}$ Copia de la nota reservada de Casasús a Ignacio Mariscal, secretario de Relaciones Exteriores, Washington, 19 de noviembre de 1905 en CONDUMEX, Archivo Limantour, fondo CDLIV, rollo 32, carpeta 7, año 1905.

${ }^{23}$ Partimos de la propuesta G. Pope Atkins, que señala que "La política exterior se transforma en política internacional cuando se asumen acciones, y otros estados [...] reaccionan, así comienza su integración" en Atkins, América, 1992 , p. 23. Si bien es cierto que la Doctrina Monroe fue comentada y provocó reacciones en el ámbito internacional desde su enunciación, como ya se señaló, ésta era la primera vez que se intentó establecer como una política internacional del continente americano con reconocimiento, pues la Doctrina Monroe cra vista como la opinión de un ex presidente o, a lo sumo, como parte de la política externa estadunidense. 
americano. Para lograrlo, expusieron su idea a uno de los países preponderantes dentro de la región latinoamericana: México, al que se le hizo saber que desempeñaría, tal vez junto con otros estados hegemónicos del área, como Brasil, Chile y Argentina, el papel de promotor de la Doctrina ante el resto de las naciones del continente.

La negociación se pretendía celebrar a través de lo que Jean Baptiste Duroselle llamaría un regateo positivo, pues se apeló a un intercambio de beneficios mutuos. Sin embargo, el hecho de que el tema se hubiera presentado en la relación diplomática planteó la necesidad de que el gobierno mexicano elaborara a su vez una política exterior $y$ asumiese un papel ante el resto del continente.

\section{LAS REACCIONES MEXICANAS}

\section{El embajador}

Ante las ideas planteadas por el presidente Roosevelt, el embajador mexicano se limitó a contestar, primero en una forma evasiva, argumentando que habría más tiempo para hablar del tema, pero después señaló que México, a lo largo de su historia, no había consumado actos expansionistas.

Además de solicitar instrucciones al secretario de Relaciones Exteriores, Ignacio Mariscal, ${ }^{24}$ Casasús pidió la in-

\footnotetext{
${ }^{24}$ Mariscal se formó como abogado en el Instituto de Ciencias y Artes de Oaxaca y fue procurador fiscal de Hacienda en dicho estado. En la década de los sesenta del siglo XIX se desempeñó como diputado federal; ministro de
}

tervención de Limantour para que se estudiara el asunto y le comunicase las decisiones que se tomaran al respecto. Comentó al ministro de Hacienda que tal vez lo único que podría pedirse a Estados Unidos sería su apoyo para que Inglaterra cediera Belice a México, pues siempre le había provocado preocupación que Inglaterra le cediera ese territorio a los estadunidenses. ${ }^{25}$

Sin embargo, el embajador se percataba de que para realizar esos proyectos se requería de una poderosa marina de guerra y en otra de sus misivas, afirmó que el hecho de que en la reunión ofrecida por el ministro chileno hubieran estado reunidos todos los representantes de América Latina, excepto los países que nada más tenían encargados de Negocios, lo había tranquilizado, porque le hacía esperar

la Suprema Corte de Justicia, oficial mayor de la Secretaria de Relaciones, secretario de la Legación mexicana en Washington; director del Tribunal de Justicia del Distrito Federal; ministro de Justicia y en 1869, fue ministro en Estados Unidos, en donde permaneció hasta 1871, año en la que por vez primera se le dio el cargo de Secretario de Relaciones, pero sólo por 16 días pues se le volvió a enviar como ministro a Estados Unidos, cargo que ocupó hasta 1877. Durante el porfiriato fue ministro de Justicia del Distrito, director de la Escuela Nacional de Jurisprudencia, ministro de Justicia e Instrucción Pública y ministro de Relaciones de 1880 a 1883 , año en que viaja a Londres como enviado especial, donde trabajó por el restablecimiento de relaciones con Gran Bretaña logrado en 1884. Regresó a la Secretaría de Relaciones en 1885 y ocupó el cargo hasta su muerte, en 1910. Cancilleres, 1992, pp. 544-601.

${ }^{25}$ Carta confidencial de Casasús a Limantour, Washington, 17 de noviembre de 1905, en CONDUMEX,. Archivo Limantour, fondo CDIIV, rollo 32, carpeta 7, año 1905 . 
que la doctrina que el presidente Roosevelt deseaba que se sostuviera, no sería la del big stick, que autorizaba la intervención de Estados Unidos en los negocios internos de los países pequeños de América porque:

Usted sabe que cada una aislada, estas diversas naciones por necesidad tendrían que aceptar cuanto quisiera el gobierno Americano; pero reunidas todas en un Congreso, son de suyo levantiscas y difíciles de manejar. ${ }^{26}$

Por otro lado, señaló que era importante aceptar para México el papel de guía en ese asunto y no dejárselo a Brasil.

\section{El ministro de Hacienda}

En su respuesta a Casasús, Limantour comentó que ni el embajador ni él se habían equivocado en la política de Roosevelt hacia Centro y Sudamérica, y que los halagos a México respondían al propósito de calmar las susceptibilidades que pudieran existir, así como al intento de borrar la desconfianza que Estados Unidos provocaría en el resto de las naciones americanas si actuaba por cuenta propia; pero que también podía implicar sentar un precedente para usarlo contra México cuando le conviniera. Por tal motivo, le parecía acertada la actitud "impasible" asumida por Casasús y consideraba importante que no desaprovechara la oportunidad para manifestar al presidente estadunidense que México no tenía el menor

\footnotetext{
${ }^{26}$ De Casasús a Limantour, Washington, 23 de noviembre de 1905 , en $i$ ibid.
}

deseo de practicar una política activa más allá de sus fronteras. ${ }^{27}$

\section{La Secretaría de Relaciones y el gabinete}

Casasús solicitó que se le giraran instrucciones respecto a las propuestas del presidente Roosevelt y el secretario Root. Al parecer, la respuesta de la Secretaría de Relaciones tardó en llegar porque se decidió reunir un consejo de ministros para tomar una decisión al respecto. Sin embargo, llama la atención que en la correspondencia del ministro de Hacienda, el embajador solicitó en forma continua que se le comunicaran las decisiones del gobierno mexicano, lo que nos hace pensar o en una falta de fluidez en las notas entre la cancillería y la embajada mexicanas o en una carencia de respuestas por parte de la Secretaría de Relaciones ${ }^{28} \mathrm{~A}$ fines de noviembre Limantour comentó los resultados de la reunión del gabinete:

\footnotetext{
${ }^{27}$ De Limantour a Casasús, México, 27 de noviembre de 1905 , en ibid.

${ }^{28}$ Hay cartas de Casasús del 11, 17, 19, 23 y 27 de noviembre de 1905 donde el embajador mexicano pide continuamente la intervención del ministro de Hacienda para que se le manden instrucciones, y es el 27 de noviembre cuando Limantour lo entera de que las instrucciones que se le enviarían serían las de esperar a que el presidente Roosevelt precisara sus intenciones respecto a México. Ibid. De hecho, Casasús manifiesta a Limantour (27 de noviembre) que tal vez Relaciones no había recibido sus notas del día 19, y Limantour le responde (30 de noviembre) que seguramente no tenía instrucciones porque la cancillería no había recibido la correspondencia.
} 
Mi temor $[\ldots]$ de que pudieran torcerse las cordialísimas relaciones que tenemos con ese gobierno, inclinaban al presidente y a Mariscal a que se hiciesen desde luego algunas concesiones a las ideas de Roosevelt; pero Corral y yo creímos, que si hemos de vernos conducidos más tarde por ese camino, no era esto motivo, sin embargo, para anticiparnos a ser dóciles. La "Doctrina Diaz" tiene que ser la base de nuestras contestaciones, mientras podamos mantenernos en ese terreno. ${ }^{29}$

De las diferentes reacciones mexicanas cabe destacar la confianza de $\mathrm{Ca}$ sasús en que si la interpretación de la Doctrina Monroe se discutía en un foro internacional como el Congreso $\mathrm{Pa}$ namericano, las naciones latinoamericanas estarían en mejor posición para defenderse actuando en conjunto ante proyectos que pudieran afectarles y que este método de política internacional era comúnmente usado por países débiles ante países considerados como potencias, es decir, en relaciones asimétricas, como en este caso.

Sobresale también la sugerencia del embajador de que sería conveniente no dejar pasar la posibilidad de que México tuviera un papel importante en el continente, pues nos remite a su percepción del país como hegemónico dentro del conjunto de las naciones hispanoamericanas y a su rivalidad con Brasil por ese liderazgo. Así mismo, resalta el recelo hacia las intenciones del gobierno estadunidense por

\footnotetext{
${ }^{29}$ De Limantour a Casasús, México, 27 de noviembre de 1905, en CONDUMEX, Archivo Limantour, fondo CDI.Iv, rollo 32 , carpeta 7 , año 1905.
}

parte del ministro Limantour y del gabinete mexicano y finalmente, que pese a que se dieron dos posiciones diferentes entre los miembros de la administración porfirista, las instrucciones fueron en el sentido de esperar a que hubiera una declaración precisa por parte de Roosevelt, sobre sus intenciones respecto a México; lo que finalmente representó una política que llevaba implícita la actitud de no ceder. A esto se refiere Duroselle cuando señala que un estado puede decidir no hacer nada. ${ }^{30}$

A principios de diciembre de 1905 Casasús comentó el mensaje anual del presidente Roosevelt ante el Congreso. Señaló que no tocó el tema de la acción común que deseaba que México y Brasil tuvieran respecto a la Doctrina Monroe y sólo se refirió a ella como "uno de los más eficaces instrumentos a favor de la paz", que no debía ser considerada por parte del gobierno de Washington como una excusa para el engrandecimiento de Estados Unidos a expensas de las repúblicas situadas al sur.

Enseguida, el embajador comentó que al parecer, Estados Unidos no quería ser único en intervenir en los conflictos americanos, sino que tal vez deseaba que en algunos problemas interviniera México y en otros Brasil. Resaltó la parte del discurso en la que Roosevelt manifestó ayudar a las naciones que lo requirieran y donde señaló que Santo Domingo había pedido la intervención estadunidense, pues ello podía servir para que México mantu-

${ }^{30}$ Duroselle, Todo, 1998, pp. 283-284. 
viera la Doctrina Díaz tal como se proclamó el 2 de abril de 1896, o con las variaciones que se le comunicaron.

Indicó que tal vez Roosevelt tenía la finalidad de persuadir a la comunidad latinoamericana, a través de sus representantes, sobre la conveniencia de sostener su interpretación de la Doctrina Monroe. No obstante, ni el presidente ni el secretario Root volvieron a tocar el tema con el embajador mexicano, sino hasta febrero de 1906 , cuando Casasús recibió la visita de William I. Buchanan, que había sido nombrado presidente de la delegación estadunidense en la conferencia de Brasil.

Ante la pregunta de Casasús sobre cuáles serían los temas que los estadunidenses deseaban tratar, Buchanan aseveró que su gobierno:

[...] no tenía la intención de someter a la próxima conferencia ninguna declaración que se refiera a la Doctrina Monroe; y diome como razón principal que la Doctrina Monroe la considera el gobierno de Estados Unidos como una base fundamental de su política exterior, y, en consecuencia, como asunto respecto del cual es innecesario tener ni la opinión, ni el apoyo de ningún otro gobierno de América. ${ }^{31}$

Casasús se limitó a no hacer un comentario al respecto, aunque lo dicho por Buchanan era un cambio importante si se tomaba en cuenta lo que le habían planteado el presidente Roosevelt y el secretario Root.

${ }^{31}$ De Casasús a Limantour, Washington, 28 de febrero de 1906, en CONDUMEx, Archivo Limantour, fondo CDLIV, rollo 38 , carpeta 6 , año 1906.

\section{REFLEXIONES FINALES}

¿Las propuestas hechas por Roosevelt y Root a la representación mexicana eran el reflejo de un proyecto de la política de Estados Unidos o de intereses personales?, ¿a qué se debió ese cambio de planes?, ¿influyó en algo el silencio del embajador mexicano o el lento intercambio de correspondencia diplomática mexicana?, existían dificultades en el entorno latinoamericano que estorbaron el proyecto?

Hasta el momento sabemos que las propuestas se realizaron por el presidente Roosevelt y el secretario Root. Sin embargo, la reacción mexicana fue de cautela, ante un posible proyecto de política exterior del gobierno de Estados Unidos.

Así mismo, es probable que la actitud mexicana hubiera desconcertado a los políticos estadunidenses. El embajador brasileño, Joaquín Nabuco, le refirió a Casasús en julio de 1906 que tuvo una conversación con el presidente Roosevelt y que éste le manifestó que había quedado muy contrariado por la actitud que México había guardado, porque él esperaba que el embajador mexicano hubiese acogido con entusiasmo sus indicaciones y no sólo había sido reservado sino que se había limitado a pedirle que precisara sus ideas a fin de poder discutirlas. ${ }^{32}$

El papel que el presidente Roosevelt asignaba a México, de promotor de la Doctrina Monroe junto con Brasil, le ayudaría a eliminar las resistencias latinoamericanas ante la nueva actitud

\footnotetext{
${ }^{32}$ Memorándum de Limantour, s. 1,, 2 de julio de 1906 en ibid.
} 
que promovió para su país hacia el continente; pero la propuesta no fue percibida así por el gobierno mexicano, sino como un compromiso que implicaba conflicto, ${ }^{33}$ pues ese reparto de atribuciones que se pretendía, implicaba un alejamiento de su política nacionalista mostrada en 1896 . El silencio fue una resistencia que se dio tal vez en el marco de dudas respecto a posibles concesiones, como la solicitud o el consentimiento expresos de la intervención estadunidense por cualquier nación latinoamericana; pero también en un ambiente de presiones por parte del presidente y el secretario de Estados Unidos, del contexto que América Latina vivía en ese entonces y la falta de fluidez en la correspondencia entre la cancillería y la embajada.

Es factible también que los funcionarios estadunidenses consideraran que era un mal momento para realizar su proyecto, debido a que Buchanan señaló la existencia de algunas discrepancias entre su gobierno y el argentino, por la publicación de una entrevista que Roosevelt tuvo en 1905 con el ex representante de ese país, Martín García Meroe, en la que el presidente atribuyó los progresos de Argentina a la pureza racial, que no existía en Brasil, Chile y Perú. ${ }^{34}$

\footnotetext{
${ }^{33}$ Podemos decir que una relación de cooperación o de colaboración es aquella en la que los intereses de los Estados aunque no sean iguales, sí necesitan ser complementarios y no contradictorios. En tanto que el conflicto origina tensión, división y discordia por divergencia de principios y relaciones asimétricas.

${ }^{34}$ De Casasús a Limantour, Washington, 28 de febrero de 1906, en CONDUMEX, Archivo
}

Además, existía la preocupación por el tema del arbitraje en la tercera conferencia; puesto que el gobierno de Perú declaró que no asistiría a la reunión si no se discutía al respecto; en tanto, Chile y México estaban dispuestos a combatir cualquier tratado de arbitraje que se quisiera llevar a cabo. Si bien es cierto que Estados Unidos no quería que el asunto formara parte del programa de la conferencia, temía que Argentina, Bolivia y Uruguay se unieran a Perú y lo apoyaran. ${ }^{35}$

El presidente y el secretario de Estado de Estados Unidos se pudieron alejar de su propósito porque sin la concurrencia de Argentina y México, dos de los tres países hegemónicos latinoamericanos de ese entonces, la promoción del corolario en la región se tornaba difícil de lograr. En ese sentido es interesante la observación que hizo el embajador Casasús respecto a que si bien no se trataría el tema de la Doctrina Monroe en la tercera conferencia, la presencia de Root en Brasil tal vez se relacionaba con la intención del gobierno estadunidense de explorar el terreno en ese país y en Argentina, sobre todo en este último, que era el foco de oposición al monroísmo. ${ }^{36}$

De haber sido esta serie de circunstancias factor importante para alterar los planes de los dirigentes políticos estadunidenses, estaríamos ante un caso en el que en un determinado contexto internacional, los miembros del grupo gobernante de potencias medias

\footnotetext{
Limantour, fondo CDLIV, rollo 38 , carpeta 6 , año 1906.

35 Ibid.

${ }^{36} \mathrm{Ibid}$.
} 
como México y Argentina pudieron frenar las intenciones originadas dentro de un poder hegemónico.

$\begin{array}{ll}\text { ARCHIVOS } & \\ \text { CONDUMEX } & \begin{array}{l}\text { Centro de Estudios Históricos } \\ \text { de México CONDUMEX. } \\ \text { Archivo Histórico de la Secre- } \\ \text { taría de Relaciones Exteriores } \\ \text { de México. }\end{array} \\ \text { Archivos Nacionales de Wash- } \\ \text { ington. }\end{array}$

\section{HEMEROGRAFÍA}

-El Imparcial.

-El Mundo.

\section{BIBLIOGRAFÍA}

-Atkins, G. Pope, América Latina en el sistema politico internacional, Gernika, México, 1992.

-Bethell, Leslie (coord.), Historia de América Latina, 7. América Latina: economía y sociedad, 1870-1930, Crítica, Barcelona, 1991.

-Cancilleres de México 1823-1911, SRE, México, 1992, t. I.

-Carreño, Alberto María, Joaquín D. Casasús, bomenajes póstumos, s.e., México, 1920.

-Cosío Villegas, Daniel (coord.), Historia moderna de México. El porfiriato. Política exterior, Hermes, México, 1973, vol. 6 .

-Deger, Robert, J., Jr., "Porfirian foreing policy and mexican nationalism: a study of cooperation and conflict in mexican-ame- rican relations, 1884-1904", tesis de doctorado, Indiana University, 1979.

- Díaz Dufoo, Carlos, Limantour, Eusebio Gómez de la Puente, México, 1910.

- Diccionario Porrúa de bistoria, biografia y geografia de México, Porrúa, México, 1981, vol. 1.

-Duroselle, Jean Baptiste, Todo imperio perecerá, FCE, México, 1998.

-Gantenbein, James W., The evolution of our latin American policy a documentary record, Octagon Books, Nueva York, 1971.

-LaFeber, Walter, The Cambridge bisto$r y$ of american foreign relations, the ame. rican search for opportunity, 1865-1913, Cambridge University Press, 1993. vol. II.

-Langley, Lester D., The United States and the caribbean in the twentieeth century, University of Georgia Press, 1989.

-Munro, Dana G., Intervention and dollar diplomacy in the caribbean, 19001921, Greenwood Press, Connecticut, 1964.

-Perkins, Dexter, Historia de la Doctrina Monroe, EUDEBA, Buenos Aires, 1964.

-Riguzzi, Paolo, "México, Estados Unidos y Gran Bretaña, 1867-1910: una difícil relación triangular", Historia Mexicana, El Colegio de México, núm. 163, 1989, México.

-Reuben Clark, Joshua, Memorandum on the Monroe Doctrine, United States Government Printting Office, Washington, 1930.

-Secretaría de Relaciones Exteriores, Un siglo de relaciones internacionales de México a través de los mensajes presidenciales, SRE, México, 1935.

-Velasco Márquez, Jesús, EUA, Síntesis de su bistoria I, Instituto Mora, México, 1988, vol, 8.

-Zermeño Padilla, Guillermo, en EUA, sintesis de su bistoria II, Instituto Mora, México, 1989. 